\title{
Data science on multimedia data: Challenges and applications
}

Published online: 2 February 2022

(C) Springer Science+Business Media, LLC, part of Springer Nature 2022

Multimedia Tools and Applications gratefully acknowledges the editorial work of the scholars listed below on the special issue entitled "Data Science on Multimedia Data: Challenges and Applications" (SI 1167).

Of 55 papers submitted, 10 were accepted for this issue after a stringent peer review process.

\section{Corresponding Guest Editor}

\section{Francesco Piccialli}

University of Naples FEDERICO II, Italy

Email: francesco.piccialli@unina.it

\section{Guest Editors}

\section{Nik Bessis}

Edge Hill University, UK

Email: Nik.Bessis@edgehill.ac.uk

\section{Gwanggil Jeon}

Incheon University, South Korea

Email: gjeon@inu.ac.kr

\section{Valeria Mele}

University of Naples FEDERICO II, Italy

Email: valeria.mele@unina.it

Publisher's note Springer Nature remains neutral with regard to jurisdictional claims in published maps and institutional affiliations. 